\title{
Altered NCAM Expression Associated with the Cholinergic System in Alzheimer's Disease
}

\author{
Bárbara Aisa $^{\mathrm{a}}$, Francisco J. Gil-Bea ${ }^{\mathrm{a}}$, Maite Solas ${ }^{\mathrm{a}}$, Mónica García-Alloza ${ }^{\mathrm{b}}$, Christopher P. Chen $^{\mathrm{c}}$, \\ Mitchell K. Lai ${ }^{\mathrm{c}, \mathrm{d}}$, Paul T. Francis ${ }^{\mathrm{e}}$ and María Javier Ramírez ${ }^{\mathrm{a}, *}$ \\ ${ }^{a}$ Department of Pharmacology, School of Medicine, Center for Applied Medical Research, University of Navarra, \\ Pamplona, Spain \\ ${ }^{\mathrm{b}}$ Division of Physiology, College of Medicine, University of Cadiz, Spain \\ ${ }^{\mathrm{c}}$ Department of Pharmacology, Yong Loo Lin School of Medicine, National University of Singapore, Singapore \\ ${ }^{\mathrm{d}}$ Dementia Research Laboratory, Department of Clinical Research, Singapore General Hospital, Singapore \\ ${ }^{\mathrm{e}}$ Wolfson Centre for Age-Related Diseases, King's College London, UK
}

Handling Associate Editor: Christoph Laske

Accepted 20 January 2010

\begin{abstract}
Neurotransmitter system dysfunction and synapse loss have been recognized as hallmarks of Alzheimer's disease (AD). Our hypothesis is that specific neurochemical populations of neurons might be more vulnerable to degeneration in AD due to particular deficits in synaptic plasticity. We have studied, in postmortem brain tissue, the relationship between levels of synaptic markers (NCAM and BDNF), neurochemical measurements (cholinacetyltransferase activity, serotonin, dopamine, GABA, and glutamate levels), and clinical data (cognitive status measured as MMSE score). NCAM levels in frontal and temporal cortex from $\mathrm{AD}$ patients were significantly lower than control patients. Interestingly, these reductions in NCAM levels were associated to an ApoE4 genotype. Levels of BDNF were also significantly reduced in both frontal and temporal regions in AD patients. The ratio between plasticity markers and neurochemical measurements was used to study which of the neurochemical populations was particularly associated to plasticity changes. In both the frontal and temporal cortex, there was a significant reduction in the ChAT/NCAM ratio in AD samples compared to controls. None of the ratios to BDNF were different between control and AD samples. Furthermore, Pearson's product moment showed a significant positive correlation between MMSE score and the ChAT/NCAM ratio in frontal cortex $\left(n=19 ; r=0.526^{*} ; p=0.037\right)$ as well as in temporal cortex $\left(n=19 ; r=0.601^{*} ; p=\right.$ 0.018) in AD patients. Altogether, these data suggest a potential involvement of NCAM expressing neurons in the cognitive deficits in $\mathrm{AD}$.
\end{abstract}

Keywords: BDNF, ChAT, cognitive deficits, frontal cortex (BA10), MMSE, plasticity, temporal cortex (BA20)

\section{INTRODUCTION}

Alzheimer's disease $(\mathrm{AD})$ is a chronic progressive neurodegenerative disorder characterized by a gradu-

\footnotetext{
*Correspondence to: Dr. María J. Ramírez, Center for Applied Medical Research, Department of Pharmacology, School of Medicine, University of Navarra, C/ Irunlarrea, 1, 31008 Pamplona, Spain. Tel.: +34 948425600; Fax: +34 948425649; E-mail: mariaja @unav.es.
}

al loss of cognitive function and is the major form of dementia affecting the elderly. Since the first reports of loss of basal forebrain acetylcholine-synthesizing neurons and associated neurochemical perturbation of presynaptic cholinergic markers $[1,2]$, neurotransmitter system dysfunction and synapse loss have been recognized as hallmarks of $\mathrm{AD}$ along with senile plaques and neurofibrillary tangles [3-7]. The cholinergic dysfunction, together with glutamatergic deficits, is considered that may trigger, in part, some of aspects of 
cognitive disturbance in AD [8-11]. Deficiencies in central serotonergic [12-15] and perhaps dopaminergic [16], but see also $[17,18]$ neural transmission may also play a critical role in some of the clinical manifestations of AD. Significant reductions in $\gamma$-amino butyric acid (GABA) levels have also been described in cases of AD [19].

Our hypothesis is that specific neurochemical populations of neurons might be more vulnerable to degeneration in $\mathrm{AD}$ due to deficits in synaptic plasticity. One class of molecules that may contribute to plasticity in the central nervous system (CNS) are glycoproteins involved in the adhesion of neural cells. These adhesion glycoproteins are believed to regulate the stabilization of synaptic junctions, neurite outgrowth, wound repair, functional plasticity, and control release of neurotransmitter. The neural cell adhesion molecule (NCAM) is a part of a family of cell-surface glycoproteins that plays key roles in normal brain development, including axonal/dendritic growth and branching, and synaptic plasticity [20-23]. Through alternative splicing, three major isoforms of NCAM are generated: NCAM120, -140 , and -180 . NCAM can be also modified by the addition of $\alpha$-2,8-polysialic acid (PSA-NCAM). At the systems level, NCAMs have been implicated as critical components in the induction of long-term potentiation (LTP) and in memory formation [20,21] NCAMs have been shown to play critical roles in ontogenetic development and are thus potential candidates in expression of age-related pathology, particularly in AD [24,25].

The aim of the present work was to study if a particular neurochemical deficit is associated to NCAM alterations in $\mathrm{AD}$. We have checked the proportion of the amount of NCAM relative to the amount of each of the neurotransmitters studied [26]. For comparative purposes, we have studied another classically used marker of plasticity, neurotrophin brain-derived neurotrophic factor (BDNF), an activity-dependent secreted protein that is critical to organization of neuronal networks and synaptic plasticity (see recent review [27]). Reduced levels of BDNF have been documented in studies of postmortem brain tissue from AD patients [28-30]. Moreover, BDNF mRNA levels were decreased in AD in the nucleus basalis of Meynert, the main source of cholinergic innervation to the cerebral cortex [31,32].

We have used clinical data and postmortem brains (frontal and temporal cortex), collected as part of a prospective community-based study of dementia [33], to study the relationship between levels of synaptic markers (BDNF and NCAM), neurochemical measurements (cholinacetyltransferase activity, serotonin,
Table 1

Demographic details

\begin{tabular}{lcc}
\hline & Control & Alzheimer's disease \\
\hline Number of patients & 16 & 19 \\
Gender (man/woman) & $9 / 7$ & $11 / 8$ \\
ApoE (2,3/4) & $-/ 16$ & $12 / 7$ \\
Braak stage & $1-2$ & $5-6$ \\
Age (years) & $78.75 \pm 2.67$ & $81.06 \pm 1.60$ \\
range & $53-99$ & $64-89$ \\
Postmortem delay (h) & $39.28 \pm 5.40$ & $48.63 \pm 6.30$ \\
pH & $6.28 \pm 0.16$ & $6.44 \pm 0.10$ \\
\hline
\end{tabular}

Values are mean \pm S.E.M. pH, standard chemical symbol, negative $\log$ of hydrogen ion concentration; S.E.M, Standard error of the mean. Values are mean \pm S.E.M. ApoE4 $=$ AD patients lacking one or two copies of the ApoE4 allele. There were no significant differences between age, postmortem delay, or brain $\mathrm{pH}$ in either control patients or those with dementia (Student t-test, $p>0.05$ ).

dopamine, GABA, and glutamate levels) and clinical data (cognitive status). On the other hand, inheritance of the $\varepsilon 4$ allele of the apolipoprotein E gene (ApoE4) is a major risk factor for the development of $\mathrm{AD}$. Although the association between ApoE4 and AD is well documented, the mechanism by which ApoE exerts an isoform-specific effect on neurons in disease is unknown. Therefore, we thought of interest to check the influence of expressing the ApoE allele on synaptic changes in AD. Based on our data, we propose that there is an association between cholinergic alterations, NCAM expression, and ApoE genotype, which might be related to the cognitive deficits in AD.

\section{MATERIAL AND METHODS}

\section{Patients and assessment of behavior}

A total of 35 individuals from the Thomas Willis Oxford Brain Collection were included in the study, 19 patients with clinical diagnosis of dementia, and 16 elderly normal controls matched for age, gender, postmortem delay, and brain $\mathrm{pH}$ (Table 1). Those patients with dementia were an autopsied subset of subjects included in a prospective study of behavioral changes in clinically diagnosed as demented patients [33]. Drug histories were recorded for all patients, and none of the patients with $\mathrm{AD}$ received cholinomimetics. At entry to the study assessment, diagnoses were made using Cambridge Mental Disorders of the Elderly Examination (CAMDEX) [34], DMS-III-R criteria [35], and NINCDS-ADRA criteria [36]. Cognitive status was assessed using the Mini-Mental State Examination (MMSE) [37]. Severity of dementia was deter- 
mined according to MMSE score at last interview before death. All tissues from control patients were examined by a pathologist and were confirmed to be free of gross neuropathology; clinical information indicated no gross neurological or psychiatric disorder.

\section{Tissue samples and neuropathology}

For all subjects, informed consent had been obtained from relatives before the removal of brain tissue at death and subsequent use of the material for research. The study had Local Ethics Committees' approval. Selection of subjects for the study was based on tissue availability, not gender, age, or disease severity. At autopsy, brains were removed and blocks corresponding to frontal (Brodmann area 10, BA10) and temporal (Brodmann area 20, BA20) cortex and were stored at $-80^{\circ} \mathrm{C}$ until processing. All patients were found to meet CER$\mathrm{AD}$ criteria [4] for a diagnosis of $\mathrm{AD}$, and all brains were Braak stage 5 or 6 as assessed by a neuropathologist. To partially mitigate the possible effects of cause of death on neurochemical determinations, brain $\mathrm{pH}$ was measured with deionised water [38] as an index of acidosis associated with terminal coma (Table 1). Brain $\mathrm{pH}$ is used as an indication of tissue quality in postmortem research, with $\mathrm{pH}>6.1$ considered acceptable [39]. All subsequent analyses were performed blind to clinical information.

\section{Cholinacetyltransferase (ChAT) activity}

ChAT activity was performed as described [14]. Frontal or temporal cortex was homogenized in 50 vol. of $0.87 \mathrm{mM}$ EDTA containing $0.1 \%$ Triton X-100 ( $\mathrm{pH}$ 7.0). Duplicated samples of $10 \mu \mathrm{l}$ from homogenates were used in the assay. The reaction mixture comprised the following: $87 \mathrm{nM}$ EDTA ( $\mathrm{pH} 7.4$ ), $0.5 \mathrm{M}$ $\mathrm{NaH}_{2} \mathrm{PO}_{4}$ (pH 7.4), $40 \mathrm{mM}$ choline chloride $3 \mathrm{M} \mathrm{NaCl}$, $2 \mathrm{nM}$ eserine salicylate, and $2 \mathrm{mM}\left[{ }^{14} \mathrm{C}\right]$-actetyl CoA (Amersham, UK). Samples were incubated at $37^{\circ} \mathrm{C}$ for $30 \mathrm{~min}$. Water was used as sample blanks. The reaction was terminated by adding $100 \mu \mathrm{l}$ of cold water. The acetylcholine product was separated using Kalignost solution: $0.5 \%$ cold di-sodiumtetraphenylborate in $15-$ $85 \%$ acetonitrile-toluene. The supernatant was then transferred to scintillation cocktail (Ecoscint TM) and radioactivity was measured. Results were expressed as percentage of control values.
Serotonin, dopamine, glutamate, and GABA measurements

Concentrations of different neurotransmitters were determined by high performance liquid chromatography (HPLC) with electrochemical detection (Waters Spheribor ${ }^{\circledR}$ S10 0DS2 4,6 $\times 150 \mathrm{~mm}$ ), including precolumn derivatization with o-phthaldehyde and $\beta$ mercapthoethanol [40] for GABA and glutamate determinations.

As previously described [14], for serotonin (5-HT) and dopamine (DA) determinations, tissue was homogenized in $20 \mathrm{v}$ of extraction mixture $(0.4 \mathrm{M}$ percloric acid; 1 mM EDTA; $0.1 \%$ metabisulphitic acid). Homogenates were centrifugated $32,500 \mathrm{~g}$ for $20 \mathrm{~min}$. The mobile phase consisted of 80:16 (v/v) mixture of buffer $\left(\mathrm{KH}_{2} \mathrm{PO}_{4} \cdot 2 \mathrm{H}_{2} \mathrm{O} 0.1 \mathrm{M}\right.$, citric acid $0.1 \mathrm{M}$, EDTA $1 \mathrm{mM}$ and octanosulphonic acid $0.74 \mathrm{mM}$; $\mathrm{pH}=$ 3). 5-HT content was calculated by comparing with a $1 \mathrm{ng}$ standard. The limit of detection was $1 \mathrm{pg} / 10 \mu \mathrm{l}$. DA content was calculated by comparing with a $0.5 \mathrm{ng}$ standard. The limit of detection was $1 \mathrm{pg} / 10 \mu \mathrm{l}$.

For GABA or glutamate determinations, tissue was homogenized in $200 \mathrm{v}$ of $0.1 \mathrm{M}$ di-sodiumtetraborate ( $\mathrm{pH}$ 9.1). Homogenates were centrifuged at 32,500 g for $20 \mathrm{~min}$. The mobile phase consisted of 72:28 (v/v) mixture of buffer $\left(\mathrm{NaH}_{2} \mathrm{PO}_{4} 0.1 \mathrm{M}, \mathrm{pH}=5.5\right)$ and methanol; the mixture was filtered and degassed through a $0.22 \mu \mathrm{m}$ nitrocellulose membrane (Millipore, UK). Glutamate and GABA content were calculated by comparing with a $2 \mathrm{ng}$ standard. The limit of detection was $20 \mathrm{pg} / 10 \mu \mathrm{l}$ for glutamate and $50 \mathrm{pg} / 10 \mu \mathrm{l}$ for GABA content.

\section{Quantification of total levels of BDNF}

The samples were processed with a commercially available sandwich enzyme-linked immunosorbent assay (ELISA) measuring BDNF protein (BDNF Emax immunoassay system, Promega Co, USA). All samples and standards were prepared in duplicate. Incubation and washing were conducted according to the manufacturer's instructions with reagents from the kit, at room temperature, sealed, and on a shaker. The optical density of the wells was analyzed in a Bio-Rad Microplate Reader at $450 \mathrm{~nm}$. A standard curve was generated from the serial BDNF standard dilutions, and BDNF protein concentrations in the samples were extrapolated directly from the standard curve. BDNF levels were expressed as $\mathrm{pg} / \mathrm{mL}$. 


\section{Quantification of total levels of NCAM}

Crude synaptosomal pellets were obtained according to a protocol from [41]. Hippocampal tissue was homogenized in 10 vol of ice-cold sucrose $(0.32 \mathrm{M})$ and HEPES ( $5 \mathrm{mM}$ ) buffer that contained a cocktail of protease inhibitors (Complete TM, Boehringer Mannheim, $\mathrm{UK}$ ) and centrifuged at $1000 \mathrm{~g}$ for $5 \mathrm{~min}$. The supernatant was then centrifuged again at $15,000 \mathrm{~g}$ for $15 \mathrm{~min}$, and the pellet resuspended in Krebs buffer. Protein concentration for each sample was estimated as previous [42]. NCAM levels were quantified according to a previously described protocol [25]. Flat bottom 96-well microplates were allowed to adsorb a coating solution $\left(\mathrm{Na}_{2} \mathrm{CO}_{3} 0.1 \mathrm{M} / \mathrm{NaHCO}_{3}, 0.1 \mathrm{M}\right)$ for $2 \mathrm{~h}$ at room temperature. The solution was removed and $50 \mu \mathrm{l}$ of pellet samples added at a concentration of $10 \mathrm{mg} / \mathrm{ml}$ to each well of polystyrene flatbottom ELISA plates. Plates were incubated overnight at $4{ }^{\circ} \mathrm{C}$ and then washed three times with $1 \mathrm{M}$ phosphate buffered saline (PBS) containing $0.05 \%$ Tween 20, pH 7.4. Additional binding sites were blocked with bovine serum albumin (BSA) (3\%) for $2 \mathrm{~h}$ at room temperature. Wells were incubated with $50 \mu \mathrm{l}$ aliquots of primary antibody Ab5032 (1:15,000 TBST; Chemicon) for $20-24 \mathrm{~h}$ at $4{ }^{\circ} \mathrm{C}$ and subsequently, $50 \mu \mathrm{l}$ aliquots of antirabbit $\mathrm{IgG}$ peroxidase conjugate antibody (1:500; Sigma, UK) were added for a $2 \mathrm{~h}$ incubation period. TMB (Promega) was used as a chromogenic substrate. The reaction was terminated by the addition of $1 \mathrm{~N}$ hydrochloric acid. Absorbancies were measured at $450 \mathrm{~nm}$ using an automatic ELISA microplate reader. Results were expressed as absorbance.

\section{ApoE genotyping}

ApoE genotyping was performed with DNA extracted from tissues according to [43].

\section{Statistical analysis}

Data were analyzed by SPSS for Windows, release 15.0. Normality was checked by Shapiro-Wilks's test $(p>0.05)$. Student's t-test was used in comparisons between controls and AD samples. The effects of demographic factors (age, postmortem delay, and brain $\mathrm{pH})$ on neurochemical variables, intercorrelation between neurochemical variables or relationships between MMSE score and neurochemical measures were determined by Pearson's or Spearman's correlation coefficients, according to the normality of variables.

\section{RESULTS}

There were no significant differences in age, postmortem delay, or brain $\mathrm{pH}$ between the control and AD groups. A summary of demographic details of controls and $\mathrm{AD}$ patients is shown in Table 1. In addition, no significant correlations between age, postmortem delay, or brain $\mathrm{pH}$ and any of the neurochemical variables studied in either controls or $\mathrm{AD}(p>0.05)$ were found. However, in a conservative analysis of data, they were included as covariates in order to avoid age or postmortem delay interferences in subsequent analysis.

\section{Neurochemical characterization of samples}

As shown in Table 2, ChAT activity in AD was reduced by $70 \%$ (BA10) or $60 \%$ (BA20) in comparison to control. Significant decreases in 5-HT, DA, and GABA levels were also found both in BA10 or BA20 samples from AD patients. Glutamate content in AD brains was not significantly different from that observed in controls.

\section{Plasticity markers in Alzheimer's disease}

NCAM levels in frontal and temporal cortex from AD patients were significantly lower than control patients (Student's t-test; $p<0.05$ ). Reductions reached $22 \%(1.00 \pm 0.10$ vs. $0.79 \pm 0.04 \mathrm{pg} / \mathrm{ml})$ in BA10 and $21.7 \%(0.51 \pm 0.04$ vs. $0.40 \pm 0.02 \mathrm{pg} / \mathrm{ml})$ in BA20 when compared to control values (Fig. 1A). None of the controls showed an ApoE4 genotype. Interestingly, these reductions in NCAM levels in AD were associated to an ApoE4 genotype: significant reductions were found in patients showing an ApoE 4 genotype (control vs. $\mathrm{AD}$, in pg/ml, BA10: $1.00 \pm 0.10$ vs. $0.71 \pm$ 0.07 ; BA20: $0.51 \pm 0.04$ vs. $0.36 \pm 0.02$ ), while no differences in NCAM levels were found in AD patients lacking one or two copies of the ApoE4 allele (control vs. $\mathrm{AD}$, in $\mathrm{pg} / \mathrm{ml}, \mathrm{BA} 10: 1.00 \pm 0.10$ vs. $0.93 \pm 0.05$; BA20: $0.51 \pm 0.04$ vs. $0.48 \pm 0.03$ ).

BDNF levels were significantly reduced (Student's t-test; $p<0.05)$ in both frontal and temporal regions in $\mathrm{AD}$ patients. BDNF reductions reached $40 \%$ $(2123.21 \pm 223.57$ vs. $1277.6044 \pm 251.24 \mathrm{pg} / \mathrm{ml})$ and $47 \%(2603.35 \pm 364.53$ vs. $1439.33 \pm 163.18 \mathrm{pg} / \mathrm{ml})$ in BA10 and BA20 regions respectively (Fig. 1B). No effects of ApoE genotype on BDNF reductions in AD patients were found. 
Table 2

Neurochemical measurements and their ratio to plasticity markers in the frontal (BA10) and temporal (BA20) cortex of controls and Alzheimer's disease (AD) patients

\begin{tabular}{|c|c|c|c|c|}
\hline & \multicolumn{2}{|c|}{ Frontal cortex (BA 10) } & \multicolumn{2}{|c|}{ Temporal cortex (BA20) } \\
\hline & Control & $\mathrm{AD}$ & Control & $\mathrm{AD}$ \\
\hline ChAT & $100.00 \pm 9.82$ & $27.68 \pm 3.55^{*}$ & $100.00 \pm 7.34$ & $38.82 \pm 7.88^{*}$ \\
\hline ChAT/NCAM & $108.15 \pm 12.52$ & $41.28 \pm 7.64^{*}$ & $214.17 \pm 16.79$ & $89.08 \pm 21.12^{*}$ \\
\hline ChAT/BDNF & $0.06 \pm 0.12$ & $0.05 \pm 0.02$ & $0.05 \pm 0.02$ & $0.04 \pm 0.01$ \\
\hline $5-\mathrm{HT}$ & $42.95 \pm 3.25$ & $25.41 \pm 1.99^{*}$ & $44.50 \pm 2.86$ & $23.95 \pm 1.39^{*}$ \\
\hline 5-HT/NCAM & $53.66 \pm 7.96$ & $37.75 \pm 5.82$ & $92.92 \pm 9.37$ & $62.62 \pm 3.91^{*}$ \\
\hline 5-HT/BDNF & $0.03 \pm 0.05$ & $0.05 \pm 0.02$ & $0.02 \pm 0.01$ & $0.02 \pm 0.01$ \\
\hline DA & $91.70 \pm 15.51$ & $43.55 \pm 5.84^{*}$ & $109.35 \pm 16.77$ & $45.45 \pm 7.07^{*}$ \\
\hline DA/NCAM & $106.63 \pm 27.05$ & $56.42 \pm 9.66$ & $187.32 \pm 37.03$ & $110.56 \pm 19.63$ \\
\hline DA/BDNF & $0.04 \pm 0.01$ & $0.09 \pm 0.03$ & $2.79 \pm 0.55$ & $4.63 \pm 0.55$ \\
\hline GABA & $704.39 \pm 63.41$ & $555.33 \pm 31.97^{*}$ & $579.94 \pm 31.72$ & $457.44 \pm 31.70^{*}$ \\
\hline GABA/NCAM & $901.06 \pm 144.66$ & $791.44 \pm 100.67$ & $1237.57 \pm 129.40$ & $1256.17 \pm 108.19$ \\
\hline GABA/BDNF & $0.47 \pm 0.11$ & $0.70 \pm 0.23$ & $0.31 \pm 0.05$ & $0.45 \pm 0.09$ \\
\hline Glutamate & $5767.11 \pm 411.73$ & $5297.91 \pm 322.52$ & $4967.06 \pm 233.81$ & $4986.11 \pm 357.35$ \\
\hline Glutamate/NCAM & $7117.01 \pm 1032.51$ & $7385.94 \pm 1013.41$ & $10150.54 \pm 825.25$ & $12990.99 \pm 1105.91$ \\
\hline Glutamate/BDNF & $3.67 \pm 0.75$ & $11.48 \pm 4.15$ & $0.05 \pm 0.01$ & $0.04 \pm 0.01$ \\
\hline
\end{tabular}

Values are mean \pm S.E.M from control $(n=16)$ and Alzheimer's disease patients $(n=19)$. ChAT activity is expressed as percentage of activity relative to control. 5-HT, dopamine (DA), GABA and glutamate levels are expressed as pg/mg of tissue. * Significantly lower than Control, Student t-test, $p<0.01$ or $p<0.001$.

A)

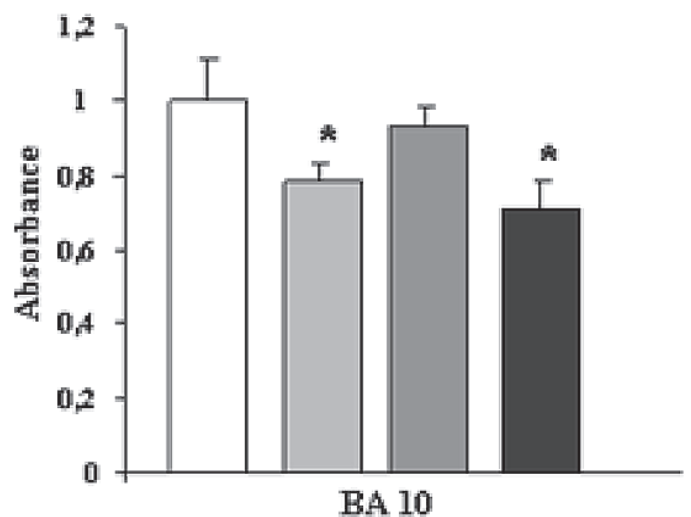

B)

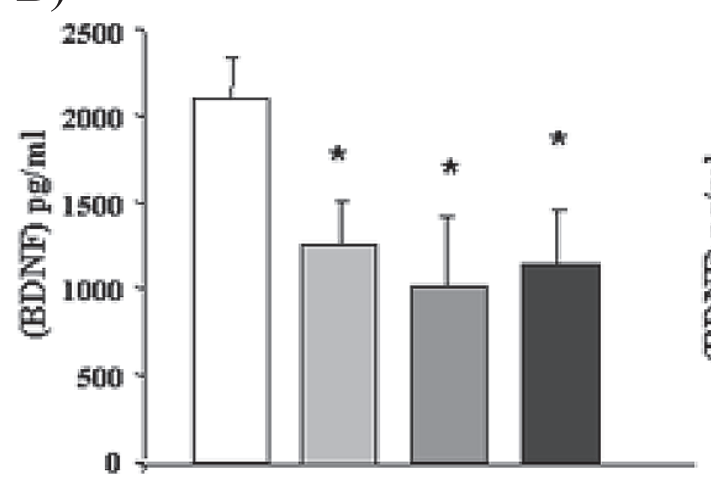

BA 10
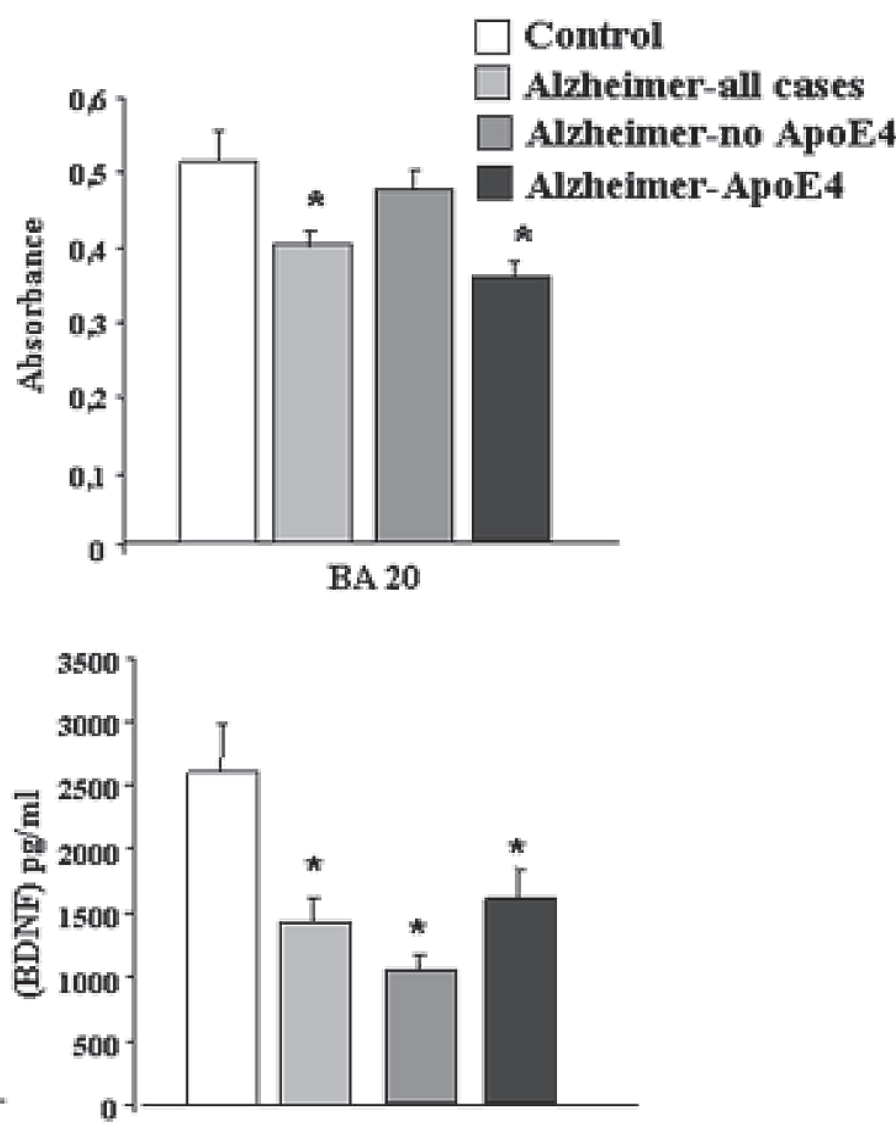

BA 20

Fig. 1. Reductions in plasticity markers in the frontal (BA10) and temporal (BA20) cortex of Alzheimer's disease (AD) patients. A) NCAM levels, expressed as absorbance; B) BDNF levels. $N=16-19 ;{ }^{*} p<0.05$ vs. control, Student's t-test. 

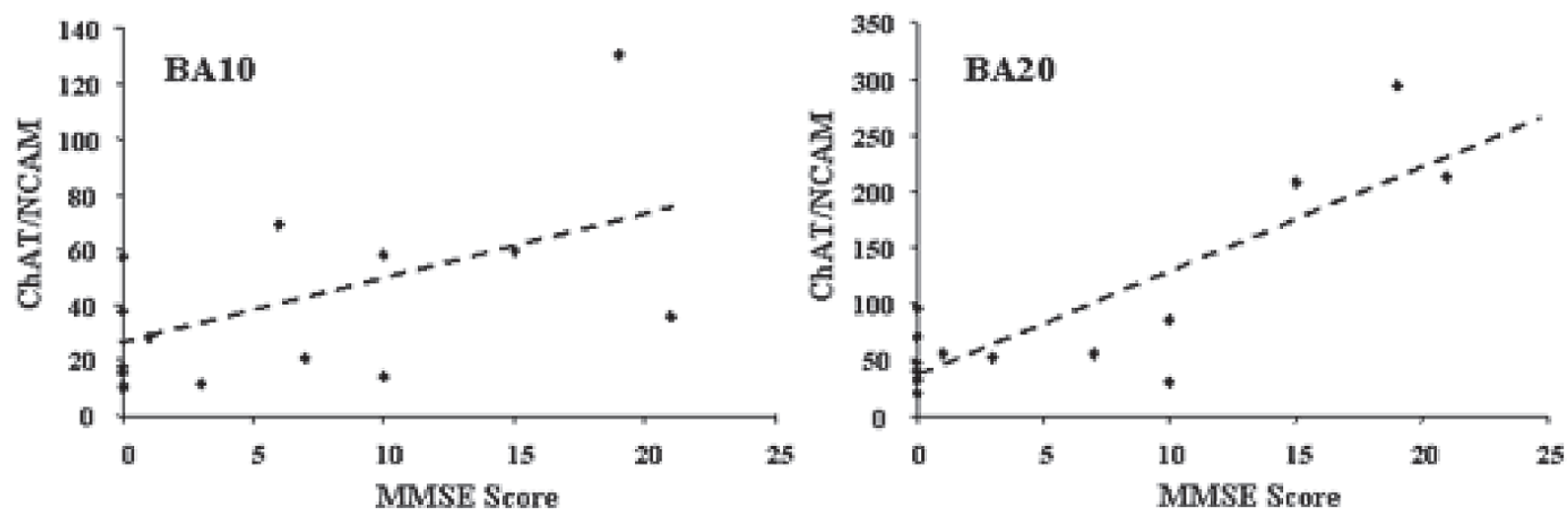

Fig. 2. Significant correlations (Pearson's correlation coefficient) between ChAT/NCAM ratio and MMSE score in the frontal (BA10, $n=19$, $r=0.526, p=0.037)$ and temporal cortex (BA20, $n=19, r=0.601, p=0.018)$ in Alzheimer's disease (AD) patients.

\section{Relationship between plasticity markers and neurochemical measurements}

The ratio between plasticity markers and neurochemical measurements was used to study which of the neurochemical populations was particularly associated to plasticity changes. In the frontal cortex, there was a significant reduction (Student's t-test; $p<0.05$ or $p<$ 0.01 ) in ChAT/NCAM and 5-HT/NCAM ratios in AD samples compared to controls. None of the ratios to BDNF were different between control and AD samples. In the temporal cortex, only the ratio ChAT/NCAM was significantly lower in AD samples. All these results are shown in Table 2.

\section{Correlations with cognitive status}

In $\mathrm{AD}$ patients mean MMSE score before death was $5 \pm 1$ (range varies between 0 and 21 ).

ChAT activity correlated to MMSE score both in the frontal (Pearson's product moment, $n=19 ; r=$ $0.524 * ; p=0.018)$ and temporal cortex $(n=19 ; r=$ $0.759 * ; p<0.001)$. NCAM levels did not correlate to MMSE score $(n=19 ; r=0.150 ; p=0.564$ for the frontal cortex, $n=19 ; r=0.142 ; p=0.599$ for the temporal cortex). Statistical analysis showed a significant positive correlation between MMSE score and the ChAT/NCAM ratio in frontal cortex $(n=19 ; r=$ $\left.0.526^{*} ; p=0.037\right)$ as well as in temporal cortex $(n=$ $19 ; r=0.601 * ; p=0.018$ ) in $\mathrm{AD}$ patients (Fig. 2). When split by ApoE genotype, these correlations were associated to an ApoE4 genotype $\left(n=7 ; r=0.796^{*}\right.$; $p=0.032$ for the frontal cortex, $n=7 ; r=0.526^{*}$; $p=0.037$ for the temporal cortex), while no correlations were found in $\mathrm{AD}$ patients lacking the ApoE4 genotype ( $n=12 ; r=0.211 ; p=0.789$ for the frontal cortex, $n=12 ; r=0.938 ; p=0.062$ for the temporal cortex). BDNF levels or BDNF ratios did not correlate to MMSE score in either cortical region. No other correlation related to other neurotransmitter systems has been found.

\section{DISCUSSION}

In the present work, we have found that: 1) NCAM levels are decreased in the frontal and temporal cortex of AD patients, and these decreases are associated with an ApoE4 genotype; and 2) the ratio of ChAT/NCAM is significantly reduced in the frontal and temporal cortex of AD patients. Furthermore, the ChAT/NCAM ratio, both in the frontal and temporal cortex, and particularly in ApoE4 carriers, was correlated to cognitive deficits in $\mathrm{AD}$. Altogether, these data suggest a potential interaction between the cholinergic system and NCAM expressing neurons, which functionally correlates to cognitive deficits.

Synaptic loss is the major neurobiological substrate of cognitive dysfunction in AD. Synaptic failure is an early event in the pathogenesis that is clearly detectable already in patients with mild cognitive impairment, a prodromal state of AD (reviewed by [44]). It progresses during the course of AD and in most early stages involves mechanisms of compensation (synaptic remodeling or synaptogenesis) before reaching a stage of decompensated function (degeneration) $[45,46]$. This synaptic degeneration in AD leads to important neurochemical alterations in the brains of AD patients and different neurotransmitter systems have been shown to be altered in AD (see review [47]). The neurochemical 
correlates of clinical dysfunctions in $\mathrm{AD}$ are not yet fully understood [48], but changes in neurochemistry could be the key to understanding the pathogenesis of cognitive deficits. Among them, the classical hallmark of $\mathrm{AD}$ is the disruption of basal forebrain cholinergic pathways and consequent cholinergic denervation of the neocortex and hippocampus. This cholinergic dysfunction has been largely related to disturbance of attentional aspects of cognition [10,11,49].

In experimental studies, NCAM expression seems to be important, and perhaps essential, for long-term information storage [50,51]. For example, administration of NCAM antibodies impaired spatial learning and passive avoidance learning in rats [52]. Administration of a synthetic peptide, which mimics NCAM activation, enhanced spatial memory [53]. Furthermore, null mutation of the NCAM gene in mice leads to impaired spatial learning and memory [54,55]. At a molecular level, expression of LTP was suppressed by the administration of antibodies against NCAM or synthetic peptides interfering with NCAM activity [56-58]. A recent study, [59] postulated that NCAM was upregulated during the early stages of spatial water maze learning, supporting the implication of this NCAM regulatory mechanism on spatial learning and memory.

No changes [60] or increased [61,45] levels of NCAM have been reported in the hippocampus of AD patients, but this increase has been related to increased neurogenesis, and may be indicative of an attempt of the brain to restore structure and function or to compensate for the damage caused by the disease. Soluble forms of NCAM are increased in the cerebrospinal fluid of both $\mathrm{AD}$ and Parkinson disease patients, but these increases seem to be related to aging and neurodegeneration and not to dementia as such [62]. In the serum samples, only levels of low molecular weight forms of NCAM correlated to severity of dementia [63]. When focusing on the cortex, according to our results, decreased levels of NCAM have been found in the frontal cortex of AD patients [64], probably reflecting synaptic loss in the illness. An interesting finding of the present work is the association of NCAM decreases in AD to an ApoE4 genotype. Inheritance of the $\varepsilon 4$ allele of the ApoE gene (ApoE4) is a major risk factor for the development of AD. Although the association between ApoE4 and AD is well documented, the mechanism by which ApoE exerts an isoform-specific effect on neurons in disease is little known. On top of already proposed mechanisms, we suggest that the presence of the ApoE4 allele might differential affect NCAM-expressing neurons [65], since neither BDNF levels (present data) nor synaptophysin or PSD95 levels [66] were affected by the ApoE4 genotype. However, it has to be noted that none of the controls showed an ApoE4 genotype. The lack of information of the effect of ApoE4 in controls prevents us to discriminate if the NCAM reduction is due to AD in ApoE4 carriers or just to the effect of the $\mathrm{E} 4$ isoform in general. It is known that ApoE4 carriers (with and without neurodegenerative disorders) have less synaptic plasticity and regeneration processes than E3 carriers [67]. On the other hand, the enhanced synaptic regenerative processes in non-carriers of the ApoE4 allele could lead to an enhanced NCAM synthesis/expression and therefore, could be masking NCAM decreases associated to AD.

As expected, considering that most of the patients in this study were severe AD (MMSE score equal or less than 10), decreases in most of the neurochemi$\mathrm{cal} /$ plasticity markers studied have been found. The ratio between plasticity markers and neurochemical measurements was used to study which of the neurochemical populations was associated with changes in NCAM and/or BDNF. Our results seem to suggest that there is a selective loss of cholinergic neurons expressing NCAM in AD. As an alternative explanation, it can be also argued that the ratio ChAT/NCAM decreases because decreases in NCAM levels in AD are smaller that decreases in ChAT activity. In any case, this relationship between ChAT-NCAM seems to be related to cognitive alterations in $\mathrm{AD}$, as suggested by present data on the correlation between ChAT/NCAM ratio and MMSE score. It is noticeable that considering the components of the ratio, only ChAT levels correlated per $s e$ with cognitive status. Therefore it seems that loss of cholinergic neurons expressing NCAM, and particularly in ApoE4 carriers, has driven the statistical correlation. It has to be considered that even though the functional link between cholinergic neurons and NCAMexpressing neurons has been described in the periphery, little is known regarding co-expression of cholinergicNCAM neurons in the CNS. In light of the present data, future studies, e.g., using immunohistochemical methods, could confirm our hypothesis of a selective loss of ChAT labeling in NCAM expressing neurons. As to the mechanism responsible for the association of ChAT-NCAM, it is of note that in the same cohort of postmortem samples used for the present study, the presence of the ApoE4 allele selectively correlated to loss of ChAT activity [68].

In addition, for comparative purposes, we have studied BDNF, another classically used marker of plasticity. It is widely accepted that alterations of BDNF levels 
or its receptors occur during normal aging and $\mathrm{AD}$ (see review, [32]). The lack of significant changes in the ratio to BDNF in any of the neurochemical markers used seem to support our hypothesis that synaptic changes in cholinergic neurons seem to be specifically related to NCAM expressing terminals. A note of caution should be mentioned at this point, pointing to the interest for future studies of measuring NCAM level, as well as the rest of the molecules implicated in cognition, in $\mathrm{AD}$ in early stages, when cognitive impairment exists but the brain is less affected by numerous pathological changes.

The present data support the notion that treatments to increase or mimic the function of NCAM might improve neuronal connectivity and cognition, perhaps through a cholinergic-mediated mechanism. NCAMmimicking peptides are being developed for their potential efficacy $[69,70]$, although the therapeutic efficacy of these NCAM-peptide mimetics remains to be tested. In a recent study the ability of C3d, a NCAM mimetic peptide, to promote ChAT activity in septal cholinergic neurons was reported [71]. On the other hand, treatment with cholinesterase inhibitors, which improve cholinergic function, increases PSA-NCAM in the hippocampus [72]. Furthermore, these enhancements correlated directly with improved spatial learning ability, suggesting that an improved memory-associated synaptic plasticity may be the fundamental mechanism underlying the disease modifying action of this kind of drugs [73]. In this sense, pharmacological manipulation of the cholinergic system may improve not only cognitive function but also plasticity disturbances in dementia.

\section{ACKNOWLEDGMENTS}

This work has been supported by Gobierno de Navarra (Dpt. Salud), and FIS (PI060200). Work by Mónica García-Alloza was funded by Ramon y Cajal contract, FIS (PS09/00969), Lóreal-UNESCO. Maite Solas has a scholarship form Ministerio de Educación y Ciencia. The tissue used for this study is part of the Thomas Willis collection.

Authors' disclosures available online (http://www.jalz.com/disclosures/view.php?id=302).

\section{REFERENCES}

[1] Whitehouse PJ, Struble RG, Clark AW, Price DL (1982) Alzheimer disease: plaques, tangles, and the basal forebrain. Ann Neurol 12, 494.
[2] Wilcock GK, Esiri MM, Bowen DM, Smith CC (1982) Alzheimer's disease Correlation of cortical choline acetyltransferase activity with the severity of dementia and histological abnormalities. J Neurol Sci 57, 407-417.

[3] Terry RD, Masliah E, Salmon DP, Butters N, DeTeresa R, Hill R, Hansen LA, Katzman R (1991) Physical basis of cognitive alterations in Alzheimer's disease: synapse loss is the major correlate of cognitive impairment. Ann Neurol 30, 572-580.

[4] Mirra SS, Heyman A, McKeel D, Sumi SM, Crain BJ, Brownlee LM, Vogel FS, Hughes JP, van Belle G, Berg L (1991) The Consortium to Establish a Registry for Alzheimer's Disease (CERAD). Part II. Standardization of the neuropathologic assessment of Alzheimer's disease. Neurology 41, 479-486.

[5] Heinonen O, Lehtovirta M, Soininen H, Helisalmi S, Mannermaa A, Sorvari H, Kosunen O, Paljärvi L, Ryynänen M, Riekkinen PJ (1995) Alzheimer pathology of patients carrying apolipoprotein E epsilon 4 allele. Neurobiol Aging 16, 505-513.

[6] Gómez-Isla T, Price JL, McKeel DW Jr, Morris JC, Growdon JH, Hyman BT (1996) Profound loss of layer II entorhinal cortex neurons occurs in very mild Alzheimer's disease. $J$ Neurosci 16, 4491-4500.

[7] Hyman BT, Trojanowski JQ (1997) Consensus recommendations for the postmortem diagnosis of Alzheimer disease from the National Institute on Aging and the Reagan Institute Working Group on diagnostic criteria for the neuropathological assessment of Alzheimer disease. J Neuropathol Exp Neurol 56, 1095-1097.

[8] Danysz W, Parsons CG (2003) The NMDA receptor antagonist memantine as a symptomatological and neuroprotective treatment for Alzheimer's disease: preclinical evidence. Int J Geriatr Psychiatry 18, 23-32.

[9] Francis PT (2003) Glutamatergic systems in Alzheimer's disease. Int J Geriatr Psychiatry 18, 15-21.

[10] Francis PT, Palmer AM, Snape M, Wilcock GK (1999) The cholinergic hypothesis of Alzheimer's disease: a review of progress. J Neurol Neurosurg Psychiatry 66, 137-147.

[11] Perry E, Walker M, Grace J, Perry R (1999) Acetylcholine in mind: a neurotransmitter correlate of consciousness? Trends Neurosci 22, 273-280.

[12] Chen CPLH, Alder JT, Bowen DM (1996) Presynaptic serotonergic markers in community-acquired cases of Alzheimer's disease: correlations with depression and neuroleptic medication. J Neurochem 66, 1592-1598.

[13] Chen CPLH, Eastwood SL, Hope T, McDonald B, Francis PT, Esiri MM (2000) Immnunocytochemical study of the dorsal and median raphenuclei in patients with Alzheimer's disease prospectively assessed for behavioural changes. Neuropathol Appl Neurobiol 26, 1-10.

[14] Garcia-Alloza M, Gil-Bea FJ, Diez-Ariza M, Chen CPLH, Francis PT, Lasheras B, Ramírez MJ (2005) Cholinergicserotonergic imbalance contributes to cognitive and behavioral symptoms in Alzheimer's disease. Neuropsycología 43, 442-449.

[15] Lai Tsang SW, Alder JT, Keene J, Hope T, Esiri MM, Francis PT, Chen CP (2005) Loss of Seorotonin 5-HT2A receptors in the postmortem temporal cortex correlates with rate of cognitive decline in AD. Psychopharmcology (Berl) 179, 673-677.

[16] Storga D, Vrecko K, Birkmayer JG, Reibnegger G (1996) Monoaminergic neurotransmitters, their precursors and metabolites in brains of Alzheimer patients. Neurosci Lett 203, 29-32. 
[17] Minger SL, Esiri MM, McDonald B, Keene J, Carter J, Hope T (2000) Cholinergic deficits contribute to behavioral disturbance in patients with dementia. Neurology 55, 1460-1467.

[18] Bierer LM, Knott PJ, Schmeidler JM, Marin DB, Ryan TM, Haroutunian V, Purohit DP, Perl DP, Mohs RC, Davis KL (1993) Post-mortem examination of dopaminergic parameters in Alzheimer's disease: relationship to noncognitive symptoms. Psychiatry Res 49, 211-217.

[19] Garcia-Alloza M, Zaldua N, Diez-Ariza M, Marcos B, Lasheras B, Gil-Bea FJ, Ramirez MJ (2006) Effect of selective cholinergic denervation on the serotonergic system: implications for learning and memory. J Neuropathol Exp Neurol 65, 1074-1081.

[20] Rønn LC, Berezin V, Bock E (2000) The neural cell adhesion molecule in synaptic plasticity and ageing. Int J Dev Neurosci 18, 193-199.

[21] Kiss JZ, Muller D (2001) Contribution of the neural cell adhesion molecule to neuronal and synaptic plasticity. Rev Neurosci 12, 297-310.

[22] Walmod PS, Kolkova K, Berezin V, Bock E (2004) Zippers make signals: NCAM-mediated molecular interactions and signal transduction. Neurochem Res 29, 2015-2035.

[23] Kleene R, Schachner M (2004) Glycans and neural cell interactions. Nat Rev Neurosci 5, 195-208.

[24] Montag-Sallaz M, Schachner M, Montag D (2002) Misguided axonal projections, neural cell adhesion molecule $180 \mathrm{mRNA}$ upregulation, and altered behavior in mice deficient for the close homolog of L1. Mol Cell Biol 22, 7967-7981.

[25] Aisa B, Elizalde N, Tordera R, Lasheras B, Del Río J, Ramírez MJ (2009) Effects of neonatal stress on markers of synaptic plasticity in the hippocampus: Implications for spatial memory. Hippocampus 19, 1222-1231.

[26] Romijn HJ, van Marle J, Janszen AW (1993) Permanent increase of the GAD67/synaptophysin ratio in rat cerebral cortex nerve endings as a result of hypoxic ischemic encephalopathy sustained in early postnatal life: a confocal laser scanning microscopic study. Brain Res 630, 315-329.

[27] Greenberg ME, Xu B, Lu B, Hempstead B (2009) New insights in the biology of BDNF synthesis and release: implications in CNS function. J Neurosci 29, 12764-12767.

[28] Phillips HS, Hains JM, Armanini M, Laramee GR, Johnson SA, Winslow JW (1991) BDNF mRNA is decreased in the hippocampus of individuals with Alzheimer's disease. Neuron 7, 695-702.

[29] Connor B, Young D, Yan Q, Faull RL, Synek B, Dragunow M (1997) Brain-derived neurotrophic factor is reduced in Alzheimer's disease. Mol Brain Res 49, 71-81.

[30] Hock C, Heese K, Hulette C, Rosenberg C, Otten U (2000) Region-specific neurotrophin imbalances in Alzheimer disease: decreased levels of brain-derived neurotrophic factor and increased levels of nerve growth factor in hippocampus and cortical areas. Arch Neurol 57, 846-851.

[31] Murer MG, Yan Q, Raisman-Vozari R (2001) Brain-derived neurotrophic factor in the control human brain, and in Alzheimer's disease and Parkinson's disease. Prog Neurobiol 63, 71-124.

[32] Tapia-Arancibia L, Aliaga E, Silhol M, Arancibia S (2008) New insights into brain BDNF function in normal aging and Alzheimer disease. Brain Res Rev 9, 201-220.

[33] Hope T, Keene J, Gedling K, Cooper S, Fairburn C, Jacoby R (1997) Behaviour changes in dementia. Int J Geriatr Psychiatry 12, 1062-1078.

[34] Roth M, Tym E, Mountjoy CQ, Huppert FA, Hendrie H, Verma S (1986) CAMDEX. A standardised instrument for the diagnosis of mental disorder in the elderly with special reference to the early detection of dementia. Br J Psychiatry 149, 698-709.

[35] American Psychiatric Association. Diagnostic and Statistical Manual of Mental Disorders (1987) III-R ed. Washington, DC: American Psychiatric Press; 1987.

[36] McKhann G, Drachman D, Folstein M, Katzman R, Price D, Stadlan EM (1984) Clinical diagnosis of Alzheimer's disease: report of the NINCDS-ADRDA Work Group under the auspices of Department of Health and Human Services Task Force on Alzheimer's Disease. Neurology 34, 939-344.

[37] Folstein MF, Folstein SE, McHugh PR (1975) Mini-mental state. A practical method for grading the cognitive state of patients for the clinician. J Psychiatr Res 12, 189-198.

[38] Bahn S, Augood SJ, Ryan M, Standaert DG, Starkey M, Emson PC (2001) Gene expression profiling in the post-mortem human brain - no cause for dismay. J Chem Neuroanat $\mathbf{2 2}$, 79-94.

[39] Kirvell SL, Esiri M, Francis PT (2006) Down-regulation of vesicular glutamate transporters precedes cell loss and pathology in Alzheimer's disease. J Neurochem 98, 939-950.

[40] Roettger VR, Goldfinger MD (1991) HPLC-EC determination of free primary amino acid concentration in cat cisternal cerbrospinal fluid. J Neurosci Methods 39, 263-270.

[41] Knafo S, Barkai E, Herrero AI, Libersat F, Sandi C, Venero C (2005) Olfactory learning-related NCAM expression is state, time, and location specific and is correlated with individual learning capabilities. Hippocampus 15, 316-325.

[42] Bradford MM (1976) A rapid and sensitive method for the quantitation of microgram quantities of protein utilizing the principle of protein-dye binding. Anal Biochem 72, 248-254.

[43] Lai MK, Tsang SW, Garcia-Alloza M, Minger SL, Nicoll JA, Esiri MM, Wong PT, Chen CP, Ramírez MJ, Francis PT (2006) Selective effects of the APOE epsilon4 allele on presynaptic cholinergic markers in the neocortex of Alzheimer's disease. Neurobiol Dis 22, 555-561.

[44] Arendt T (2009) Synaptic degeneration in Alzheimer's disease. Acta Neuropathol 118, 167-179.

[45] Mikkonen M, Soininen H, Tapiola T, Alafuzoff I, Miettinen R (1999) Hippocampal plasticity in Alzheimer's disease: changes in highly polysialylated NCAM immunoreactivity in the hippocampal formation. Eur J Neurosci 11, 1754-1764.

[46] Mikkonen M, Soininen H, Alafuzof I, Miettinen R (2001) Hippocampal plasticity in Alzheimer's disease. Rev Neurosci 12, 311-325.

[47] Lai MK, Ramírez MJ, Tsang S, Francis PT (2007) Alzheimer's disease is a neurotransmitter disease. In: Neurobiology of Alzheimer's disease. Oxford University Press, pp. 245-283.

[48] Esiri MM (1996) The basis for behavioural disturbances in dementia. J Neurol Neurosurg Psychiatry 61, 127-130.

[49] Terry Jr AV, Buccafusco JJ (2003) The cholinergic hypothesis of age and Alzheimer's disease-related cognitive deficits: recent challenges and their implications for novel drug development. J Pharmacol Exp Ther 306, 821-827.

[50] Sandi C. Stress, cognitive impairment and cell adhesion molecules. Nat Rev Neurosci 5, 17-30.

[51] Conboy L, Bisaz R, Markram K, Sandi C (2010) Role of NCAM in emotion and learning. Adv Exp Med Biol 663, 271296.

[52] Arami S, Jucker M, Schachner M, Welzl H (1996) The effect of continuous intraventricular infusion of L1 and NCAM antibodies on spatial learning in rats. Behav Brain Res 81, 81-87. 
[53] Cambon K, Hansen SM, Venero C, Herrero AI, Skibo G, Berezin V, Bock E, Sandi C (2004) A synthetic neural cell adhesion molecule mimetic peptide promotes synaptogenesis, enhances presynaptic function, and facilitates memory consolidation. J Neurosci 24, 4197-4204.

[54] Cremer H, Lange R, Christoph A, Plomann M, Vopper G, Roes J, Brown R, Baldwin S, Kraemer P, Scheff S (1994) Inactivation of the N-CAM gene in mice results in size reduction of the olfactory bulb and deficits in spatial learning. Nature 367, 455-459.

[55] Stork O, Welzl H, Wolfer D, Schuster T, Mantei N, Stork S, Hoyer D, Lipp H, Obata K, Schachner M (2000) Recovery of emocional behaviour in neural cell adhesion molecule (NCAM) null mutant mice through transgenic expression of NCAM180. Eur J Neurosci 12, 3291-3306.

[56] Lüithi TE, Brodbeck DL, Jenö P (1994) Identification of a 70 $\mathrm{kD}$ protein with sequence homology to squid neurofilament protein in glial cells of the leech CNS. J Neurobiol 25, 70-82.

[57] Rønn LC, Bock E, Linnemann D, Jahnsen H (1995) NCAMantibodies modulate induction of long-term potentiation in rat hippocampal CA1. Brain Res 677, 145-151.

[58] Cremer H, Chazal G, Carleton A, Goridis C, Vincent JD, Lledo PM (1998) Long-term but not short-term plasticity at mossy fiber synapses is impaired in neural cell adhesion moleculedeficient mice. Proc Natl Acad Sci U S A 95, 13242-13247.

[59] Venero C, Herrero AI, Touyarot K, Cambon K, LopezFernandez MA, Berezin V, Bock E, Sandi C (2006) Hippocampal up-regulation of NCAM expression and polysialylation plays a key role on spatial memory. Eur J Neurosci 23, 15851595.

[60] Gillian AM, Brion JP, Breen KC (1994) Expression of the neural cell adhesion molecule (NCAM) in Alzheimer's disease. Neurodegeneration 3, 283-291.

[61] Jin K, Peel AL, Mao XO, Xie L, Cottrell BA, Henshall DC, Greenberg DA (2004) Increased hippocampal neurogenesis in Alzheimer's disease. Proc Natl Acad Sci U S A 101, 343-347.

[62] Strekalova H, Buhmann C, Kleene R, Eggers C, Saffell J, Hemperly J, Weiller C, Müller-Thomsen T, Schachner M (2006) Elevated levels of neural recognition molecule L1 in the cerebrospinal fluid of patients with Alzheimer disease and other dementia syndromes. Neurobiol Aging 2, 1-9.

[63] Todaro L, Puricelli L, Gioseffi H, Guadalupe Pallotta M, Lastiri J, Bal de Kier Joffé E, Varela M, Sacerdote de Lustig
E (2004) Neural cell adhesion molecule in human serum. In creased levels in dementia of the Alzheimer type. Neurobiol Dis 15, 387-393.

[64] Yew DT, Li WP, Webb SE, Lai HW, Zhang L (1999) Neurotransmitters, peptides, and neural cell adhesion molecules in the cortices of normal elderly humans and Alzheimer patients: a comparison. Exp Gerontol 34, 117-133.

[65] Poirier J, Delisle MC, Quirion R, Aubert I, Farlow M, Lahiri D, Hui S, Bertrand P, Nalbantoglu J, Gilfix BM, Gauthier S (1995) Apolipoprotein E4 allele as a predictor of cholinergic deficits and treatment outcome in Alzheimer disease. Proc Natl Acad Sci U S A 92, 12260-12264.

[66] Love S, Siew LK, Dawbarn D, Wilcock GK, Ben-Sholmo Y, Allen SJ (2006) premorbid effect of APO on synaptic proteins in human temporal neocortex. Neurobiol Aging 27, 797-803.

[67] Cedazo-Mínguez A. (2007) Apolipoprotein E and Alzheimer's disease: molecular mechanisms and therapeutic opportunities. J Cell Mol Med 11, 1227-1238.

[68] Lai MK, Tsang SW, Garcia-Alloza M, Minger SL, Nicoll JA, Esiri MM, Wong PT, Chen CP, Ramírez MJ, Francis PT (2006) Selective effects of the APOE epsilon4 allele on presynaptic cholinergic markers in the neocortex of Alzheimer's disease. Neurobiol Dis 22, 555-561.

[69] Berezin V, Bock E (2004) NCAM mimetic peptides: Pharmacological and therapeutic potential. J Mol Neurosci 22, 33-39.

[70] Borcel E, Pérez-Alvarez L, Herrero AI, Brionne T, Varea E, Berezin V, Bock E, Sandi C, Venero C (2008) Chronic stress in adulthood followed by intermittent stress impairs spatial memory and the survival of newborn hippocampal cells in aging animals: Prevention by FGL, a peptide mimetic of neural cell adhesion molecule. Behav Pharmacol 19, 41-49.

[71] Burgess A, Saini S, Weng YQ, Aubert I (2009) Stimulation of choline acetyltransferase by $\mathrm{C} 3 \mathrm{~d}$, a neural cell adhesion molecule ligand. J Neurosci Res 87, 609-616.

[72] Murphy KJ, Regan CM (1999) Sequential training in separate paradigms impairs second task consolidation and learningassociated modulations of hippocampal NCAM polysialylation. Neurobiol Learn Mem 72, 28-38.

[73] Farlow M, Anand R, Messina Jr J, Hartman R, Veach J (2000) A 52-week study of the efficacy of rivastigmine in patients with mild to moderately severe Alzheimer's disease. Eur Neurol 44, 236-241. 